\title{
DESCONCENTRAÇÃO E INTERIORIZAÇÃO DA ECONOMIA FLUMINENSE NO PERÍODO DE I 996 A 2005
}

Paulo M. de Souza ${ }^{1}$

Niraldo José Ponciano ${ }^{2}$

Marlon Gomes $\mathrm{Ney}^{3}$

Henrique T. C. Mata ${ }^{4}$

\section{Resumo}

O objetivo da pesquisa foi analisar o processo de desconcentração e interiorização da economia do Estado do Rio de Janeiro na última década, mais especificamente o período de 1996 a 2005. Com o uso do modelo estrutural diferencial, fez-se uma análise da evolução do pessoal ocupado nas diversas mesorregiões geográficas que compõem o Estado, considerando-se as atividades: indústria extrativa mineral, indústria de transformação, serviços industriais de utilidade pública, indústria da construção civil, comércio, serviços, administração pública e agropecuária. Os resultados evidenciaram a ocorrência de desconcentração industrial, com redução da participação da região metropolitana no emprego e na renda, o que se deve, principalmente, à expansão da indústria extrativa mineral associada ao petróleo.

\footnotetext{
${ }^{1}$ Doutor em Economia Aplicada e Professor na Universidade Estadual do Norte Fluminense, UENF. pmsouza@uenf.br

${ }^{2}$ Doutor em Economia Aplicada e Professor na Universidade Estadual do Norte Fluminense, UENF. ponciano@uenf.br

${ }^{3}$ Doutor em Economia Aplicada e Professor na Universidade Estadual do Norte Fluminense, UENF marlongomes@hotmail.com

${ }^{4}$ Doutor em Economia Aplicada e Professor na Universidade Federal da Bahia, UFBA. hnrmata@ufba.br
} 
Palavras-chave: economia regional, modelo estrutural-diferencial, petróleo.

\section{Abstract}

The objective of the research was to analyze the process of reduction in the concentration of the Rio de Janeiro's economy, during the last decade (from 1996 to 2005). It was considered the empolyment in the activities: mineral extraction industry, manufacturing industry, industrial utility services, construction industry, trade, services, public administration and farming. The employment evolution, by regions of Rio de Janeiro, was studied with the shift-share analysis. By the results, Rio de Janeiro's economy became less concentrated, reducing the participation of the metropolitan region in the job and the income. The growth of the mineral extraction industry, associate to the oil, is one of the main causes of these changes.

Key-words: regional economy, shift-share analysis, oil.

\section{Introdução}

A década de oitenta, considerada a década perdida, foi caracterizada pela queda da taxa de crescimento do PIB, acentuada elevação da dívida externa, redução do emprego e intensificação da inflação. Como desafios, ela legou à década seguinte as preocupações com a questão monetária e a retomada da trajetória de modernização e crescimento. (FERNANDES, 2007)

As reformas por que passou a economia brasileira no início da década de noventa, aprofundadas com o Plano Real, não colocaram o país numa trajetória de crescimento sustentado. A aposta de que a abertura da economia ao comércio e aos fluxos de capitais internacionais, o programa de privatizações e o fim do processo inflacionário promoveriam um ambiente competitivo, eliminando distorções de mercado, gerando aumentos de produtividade, proporcionando um ambiente estável para os investimentos e trazendo, como resultado, um "círculo virtuoso" de crescimento com estabilidade, mostrou seus equívocos. (DAMASCENO; ARAÚJO, 2003) ${ }^{5}$

Esse período assinala a crise, iniciada na década anterior, do modelo de desenvolvimento até então adotado pelo governo brasileiro, intrinsecamente vinculado à forte presença estatal nos investimentos e no planejamento

${ }_{5}^{5}$ A taxa de crescimento médio anual do PIB foi de $2,41 \%$, no período $1991-2002$, e de $2,02 \%$, no período 1996-2002; taxas que são, inclusive, inferiores à taxa de crescimento da década de 80, de $2,9 \%$, considerada a década perdida. da economia. A redução da presença estatal e a maior abertura do mercado nacional à concorrência internacional, especialmente a partir dos anos 90, evidenciaram a incapacidade da produção interna de competir com os produtos estrangeiros, o que levou várias empresas, nacionais ou não, a se reestruturarem organizacional e produtivamente. (ALMEIDA, 2002)

Conforme Barral Neto e Silva Neto (2006), o Estado do Rio de Janeiro foi um dos mais impactados por este contexto de mudanças, que teve como efeito direto o agravamento de sua crise. O processo de desenvolvimento econômico fluminense, em grande parte associado às ações do Governo Federal, que atuava como demandante de suas empresas, ressentiu-se da menor presença deste último, num contexto de "reforma do Estado". Desse contexto fez parte ainda a abertura do mercado nacional à alta competição com produtos estrangeiros, expondo à competição importantes setores produtivos, como o naval, o sucro-alcooleiro e o metalúrgico. (SILVA NETO, 2006)

A disparidade econômica entre as regiões do Estado, caracterizada pela concentração das atividades econômicas e da geração de renda na região metropolitana, é um fator adicional a acirrar os efeitos decorrentes das mudanças citadas. A região metropolitana, conforme Santos (2003), responde praticamente por toda a economia fluminense, que não apresenta articulação forte entre as suas regiões. Segundo o autor, o Rio de Janeiro é o Estado com maior concentração espacial em termos de produto e de população.

Diante da necessidade de reduzir essa concentração, vêm sendo adotadas medidas visando à interiorização industrial, mediante a criação de bases industriais e sistemas de apoio tecnológico em diferentes pontos do território fluminense. Abordando o período de 1985 e 2001, Alcântara (2005) ressalta as mudanças ocorridas nas atividades de extração de petróleo, extração de minerais não-metálicos, vestuário, couros, madeira, celulose, edição, fabricação de coque e refino de petróleo, borracha e plástico, minerais não-metálicos, metal, as máquinas para escritório e equipamentos de informática, materiais elétricos, material eletrônico, os equipamentos médico-hospitalares, automobilística, móveis e indústrias diversas. Segundo a autora, essas atividades foram responsáveis por certa desconcentração da economia do Estado.

Além de ser uma tendência mundial, o processo de interiorização industrial está relacionado, segundo Barral Neto e Silva Neto (2006), aos novos papéis dos Estados e dos municípios, surgidos ao final da década de 80. A partir da constituição 1988, os governos estaduais e municipais ganharam mais autonomia, passando a não depender exclusivamente do planejamento central para formular suas políticas econômicas. 
Como destacado por Silva (2004), a economia fluminense, na década de noventa, passou por dois momentos distintos: de início, a permanência do ambiente crítico vivido nos anos 1980, e a seguir uma inflexão positiva em sua trajetória de esvaziamento econômico. Essa reversão na trajetória de esvaziamento econômico ocorre a partir da segunda metade da década de 1990 quando a economia do Estado do Rio de Janeiro passou a emitir alguns sinais de recuperação, elevando, inclusive, sua participação na economia nacional.

Essa nova dinâmica está relacionada, principalmente, ao crescimento da atividade petrolífera, que apresenta forte influência sobre a economia, seja pelos ganhos obtidos diretamente da atividade extrativa e pelo seu efeito multiplicador sobre as demais cadeias produtivas, seja por seus efeitos sobre o balanço de pagamentos e as contas públicas. (FERNANDES, 2007) Tamanha tem sido a influência desse setor que, segundo Silva Neto (2006), as perspectivas de retomada do processo de crescimento econômico do Estado relacionam-se, de forma estreita, com a indústria do petróleo, situada na Bacia de Campos. Tal fato, além disso, coloca a região norte fluminense, base desse processo, como um polo de destaque econômico.

\section{Objetivos}

O objetivo geral da pesquisa é abordar o processo de desconcentração e interiorização da economia do Estado do Rio de Janeiro na última década, mais especificamente o período de 1996 a 2005. Para isso, faz-se uma análise da evolução do pessoal ocupado nas diversas mesorregiões geográficas que compõem o Estado, considerando-se as atividades: indústria extrativa mineral, indústria de transformação, serviços industriais de utilidade pública, indústria da construção civil, comércio, serviços, administração pública e agropecuária.

\section{Metodologia}

\section{O modelo estrutural-diferencial}

Para analisar a evolução do pessoal ocupado nas diversas atividades que compõem a economia do Estado do Rio de Janeiro, pretende-se empregar o modelo estrutural-diferencial. Esse modelo, em sua forma original ou ampliada tem sido empregado em vários estudos, como é o caso de Souza (2007), Souza e outros (2007), Santos (2000), Souza e Souza (2004) Pereira e Campanile (1999).
Embora o método não permita inferir sobre as causas do maior dinamismo de determinado setor ou as vantagens locacionais de determinada região, ele representa, conforme Haddad e Andrade (1989), um modelo analítico capaz de gerar informações importantes para a realização de pesquisas adicionais sobre problemas de desenvolvimento regional. É nessa perspectiva, isto é, a de gerar informações que permitam embasar pesquisas futuras sobre a distribuição espacial da economia fluminense, que esse modelo é empregado.

Através desse modelo, espera-se poder comparar o crescimento do pessoal ocupado, nas diversas atividades, bem como identificar a presença de fatores, em nível regional e municipal, que contribuem para explicar esse comportamento. Nesse método, cuja descrição baseia-se em Haddad e Andrade (1989), Pereira (1997) e Pereira e Campanile (1999), admite-se que o crescimento de determinado setor $i$, numa dada região $j$, pode ser decomposto num efeito estrutural ou proporcional e num efeito diferencial ou regional. O efeito estrutural reflete a composição setorial regional, indicando, quando positivo, a predominância de setores mais dinâmicos da economia, ou seja, de setores com taxa de crescimento maior do que a do conjunto da economia. Já o efeito diferencial ou regional indica, quando positivo, o setor que está crescendo mais numa região do que em outras, refletindo assim a presença de fatores locais propiciadores desse diferencial de crescimento, e evidenciando que a região se apresenta especialmente vantajosa para a produção desse setor, relativamente ao país.

Sejam $E_{j}^{0}$ e $E_{j}^{t}$ o pessoal ocupado no setor i da região j nos períodos inicial e final, respectivamente. Assim, a variação real do pessoal ocupado entre esses períodos $\left(\Delta E_{j}^{t}\right.$ ) é equivalente a:

$$
\Delta E_{j}^{t}=E_{j}^{t}-E_{j}^{0}
$$

Admitindo como $e_{i j}$ a taxa de crescimento do pessoal ocupado no setor i da região $\mathrm{j}$, entre os tempos inicial e final, obtida por

$$
e_{i j}=\frac{E_{j}^{t}}{E_{j}^{0}}
$$

resulta que o montante do pessoal ocupado no período final, no setor 
i da região j $\left(E_{j}^{t}\right)$, pode ser expresso como o produto do pessoal ocupado inicialmente no setor i da região j $\left(E_{j j}^{0}\right)$ pela taxa de crescimento desse mesmo setor na mesma região $\left(e_{i j}\right)$, ou seja:

$$
E_{j}^{t}=E_{j}^{0} \cdot \frac{E_{j}^{t}}{E_{j}^{0}}=E_{j}^{0} \cdot e_{j}
$$

Substituindo a equação (3) na expressão da variação real do pessoal ocupado no setor i da região j entre os períodos inicial e final (1), obtém-se

$$
\Delta E_{j}^{t}=E_{j}^{t}-E_{j}^{0}=E_{j}^{0} \cdot e_{j}-E_{j}^{0}=E_{j}^{0}\left(e_{j}-1\right)
$$

Define-se a taxa de crescimento do pessoal ocupado no setor i no país $\left(e_{i}\right)$ como a divisão entre o montante do pessoal ocupado no setor i do país no período final $\left(E_{i}^{t}\right)$ pelo montante inicialmente ocupado no setor i do país $\left(E_{i}^{0}\right)$, isto é,

$$
e_{i}=\frac{E_{i}^{t}}{E_{i}^{0}}
$$

Similarmente, a taxa de crescimento do pessoal ocupado no país entre os instantes inicial e final como a divisão do total do pessoal ocupado ao final do período $\left(E^{t}\right)$ pelo pessoal ocupado no início $\left(E^{0}\right)$, ou seja,

$$
e=\frac{E^{t}}{E^{0}}
$$

Somando-se e subtraindo-se essas taxas de crescimento na expressão (4), ou seja, fazendo

$$
\Delta E_{j}^{t}=E_{j}^{t}-E_{j}^{0}=E_{j}^{0} \cdot\left(e_{j}-1+e-e+e_{i}-e_{i}\right)
$$

e, multiplicando e reagrupando os termos, obtém-se:

$$
\Delta E_{j}^{t}=E_{j}^{t}-E_{j}^{0}=E_{j}^{0}(e-1)+E_{j}^{0}\left(e_{i}-e\right)+E_{j}^{0}\left(e_{j}-e_{i}\right)
$$

6 | Nexos Econômicos - CME-UFBA que é a expressão para a decomposição da variação do pessoal ocupado no setor i entre o período inicial e final, na região j. Nessa expressão:

$E_{j}^{0}(e-1)$ corresponde à variação teórica do pessoal ocupado em nível regional, que seria obtida caso a região crescesse à taxa de crescimento do emprego nacional;

$E_{j}^{0}\left(e_{i}-e\right)$ é a variação estrutural ou proporcional que, se positiva, representa uma situação em que o setor i cresce acima da média do país; e,

$E_{j}^{0}\left(e_{j}-e_{i}\right)$ representa o efeito diferencial ou regional, indicando a existência ou não de vantagens locacionais, ou seja, de condições propícias ao crescimento do setor. Se positivo, indica que o setor i cresce mais na região j que em outras.

O efeito total é obtido pela soma dos efeitos estrutural e diferencial, e mede a diferença entre o crescimento real ou efetivo apresentado pelo Estado e o crescimento teórico, isto é, aquele que seria obtido caso crescesse à taxa do país como um todo. Assim, retomando a expressão (7) e fazendo uso da equação (3), demonstra-se que o efeito total corresponde a:

$$
\Delta E_{j}^{t}-E_{j}^{0}(e-1)=E_{j}^{0}\left(e_{i}-e\right)+E_{j}^{0}\left(e_{j}-e_{i}\right)=E_{j}^{0}\left(e_{j}-e\right)
$$

Da expressão (8), pode-se concluir que os efeitos totais positivos correspondem a setores dinâmicos, que estariam crescendo, em termos reais, mais do que cresceriam se estivem evoluindo à taxa nacional.

No presente estudo, o que se busca não é analisar as diferenças de competitividade entre setores ou as especificidades locacionais/regionais que os favorecem. Assim, a variação teórica do pessoal ocupado em nível regional (no presente contexto, o termo regional poderá referir-se a uma das mesorregiões estudadas ou aos municípios), quando negativa, indicaria situações de redução do total do pessoal ocupado na economia do Estado do Rio de Janeiro, isto é (e $<1)$. A variação estrutural ou proporcional, quando positiva, indica que a atividade analisada (i) cresce mais do que $o$ total do pessoal ocupado na economia fluminense (ei $>$ e), ou seja, exibe crescimento maior do que o observado para o conjunto das atividades consideradas. Já o efeito diferencial ou regional indica a existência ou não de condições regionais/municipais que favoreçam o aumento do montante de trabalhadores ocupados em determinada atividade. Se positivo, esse efeito indicaria a presença de fatores regionais/municipais propícios ao crescimento 
de determinada atividade, que estaria evoluindo a taxas mais elevadas nessa (e) região/município do que na economia do Estado (eij > ei). O efeito total, por sua vez, representa a diferença entre o crescimento efetivo da mão de obra ocupada numa região ou município e seu crescimento teórico, isto é aquele que ele teria caso evoluísse a uma taxa idêntica à do crescimento do emprego na economia do Estado do Rio de Janeiro. Assim, efeito total positivo representaria, para uma atividade específica, numa região ou município específico, um comportamento dinâmico, pois sua evolução seria maior do que o crescimento do pessoal ocupado na economia do Estado.

\section{Variáveis e fonte dos dados}

As informações sobre o pessoal ocupado nas atividades econômicas, em nível de mesorregiões, foram obtidas na Fundação CIDE - Centro de Informações e Dados do Rio de Janeiro. Esses dados correspondem às informações publicadas originalmente na Relação Anual de Informações Sociais - RAIS, do Ministério do Trabalho e Emprego. As informações provenientes dessa fonte são mais adequadas a análises estruturais do mercado de trabalho formal, como é o caso da pesquisa, sendo, portanto, mais recomendáveis do que as informações provenientes do Cadastro Geral de Empregados e Desempregados - CAGED, indicadas para análises de conjuntura do mercado de trabalho formal. (BRASIL, 2008)

\section{Resultados e discussão}

Nas Tabelas 1 e 2 são apresentados os resultados da decomposição da variação do pessoal ocupado nas mesorregiões do Estado, entre os anos de 1996 e 2000, em variação teórica, variação estrutural e variação regional. Pode-se observar que a variação teórica do pessoal ocupado, que seria obtida caso a mão de obra ocupada se elevasse à taxa de crescimento do total do pessoal ocupado no Estado do Rio de Janeiro, é positiva para todas as atividades consideradas. Tal resultado decorre do fato de que houve, no período, um crescimento do total do pessoal ocupado no Estado.

Observa-se ainda que a variação estrutural foi negativa para a maior parte das atividades, com exceção dos setores de Comércio e Serviços. Isso evidencia que, durante esse período, o crescimento do emprego nesses setores se deu a uma taxa maior do que a taxa de crescimento do emprego total, ou seja, esses setores apresentaram maior dinamismo do que os demais.
Com relação ao efeito regional, observa-se claramente o menor dinamismo da região metropolitana do Estado, na qual, com exceção do setor Indústria extrativa mineral, esse efeito é negativo para todas as demais atividades. De um modo geral, as demais regiões apresentam maior dinamismo, com efeito regional positivo para a maior parte dos setores, com exceção de: Serviços e Administração pública, na região Noroeste; Indústria extrativa mineral, Indústria de transformação e Serviços industriais de utilidade pública, na região Norte; Serviços industriais de utilidade pública, na região Serrana; Serviços industriais de utilidade pública e Indústria extrativa mineral, nas Baixadas Litorâneas; Indústria de transformação e Agropecuária, no Médio Paraíba; Indústria de transformação e Indústria da construção civil, no Centro-Sul; e Indústria de transformação, Indústria da construção civil e Agropecuária, na Costa Verde. Esses resultados podem, portanto, ser tomados como evidência em favor de uma interiorização da economia do Estado do Rio de Janeiro no período em questão, caracterizada pelo maior dinamismo das economias situadas fora da região metropolitana.

Tabela 1 - Decomposição da variação total do pessoal ocupado nos efeitos teórico (T), estrutural (E) e regional (R), para as regiōes Metropolitana, Noroeste Fluminense, Norte Fluminense e Serrana, 1996-00

\begin{tabular}{|c|c|c|c|c|c|c|c|c|c|c|c|c|}
\hline \multirow{2}{*}{ Atividade } & \multicolumn{3}{|c|}{ Metropolitana } & \multicolumn{3}{|c|}{ Noroeste } & \multicolumn{3}{|c|}{ Norte } & \multicolumn{3}{|c|}{ Serrana } \\
\hline & $\mathrm{T}$ & $\mathrm{E}$ & $\mathrm{R}$ & $\mathrm{T}$ & $\mathrm{E}$ & $\mathrm{R}$ & $\mathrm{T}$ & $\mathrm{E}$ & $\mathrm{R}$ & $\mathrm{T}$ & $E$ & $\mathrm{R}$ \\
\hline Ind. Extr. Mineral & 24 & -839 & 643 & 2 & -69 & 281 & 50 & -1743 & -1389 & 1 & -50 & 81 \\
\hline Ind. Transformação & 1674 & -47949 & -2295 & 26 & -741 & 1861 & 81 & -2321 & -463 & 196 & -5607 & 2536 \\
\hline Serv. I. U. Pública & 276 & -8812 & -237 & 2 & -79 & 107 & 6 & -192 & -148 & 17 & -528 & -372 \\
\hline Ind. Constr. Civil & 649 & -20985 & -5411 & 3 & -97 & 176 & 29 & -945 & 4197 & 25 & -818 & 815 \\
\hline Comércio & 2276 & 27967 & -15833 & 34 & 418 & 855 & 91 & 1118 & 3490 & 140 & 1725 & 1954 \\
\hline Serviços & 6008 & 92527 & -21853 & 47 & 723 & -900 & 165 & 2545 & 7747 & 253 & 3904 & 549 \\
\hline Administr. Pública & 3117 & -27595 & -18635 & 53 & -468 & -57 & 88 & -776 & 1510 & 86 & -758 & 5310 \\
\hline Agropecuária & 36 & -835 & -923 & 14 & -330 & 354 & 29 & -677 & 1274 & 23 & -538 & 684 \\
\hline
\end{tabular}

Tabela 2- Decomposição da variação total do pessoal ocupado nos efeitos teórico (T), estrutural (E) e regional (R), para as regiōes Baixadas Litorâneas, Médio Paraíba, Centro-Sul Fluminense e Costa Verde, 1996-00

\begin{tabular}{|c|c|c|c|c|c|c|c|c|c|c|c|c|}
\hline \multirow{2}{*}{ Atividade } & \multicolumn{3}{|c|}{ Baixadas Litorânea } & \multicolumn{3}{|c|}{ Médio Paraíba } & \multicolumn{3}{|c|}{ Centro-Sul } & \multicolumn{3}{|c|}{ Costa Verde } \\
\hline & $\mathrm{T}$ & $\mathrm{E}$ & $\mathrm{R}$ & $\mathrm{T}$ & $E$ & $\mathrm{R}$ & $\mathrm{T}$ & $\mathrm{E}$ & $\mathrm{R}$ & $\mathrm{T}$ & $E$ & $\mathrm{R}$ \\
\hline Ind. Extr. Mineral & 11 & -377 & -279 & 2 & -87 & 400 & 1 & -50 & 8 & 4 & -124 & 256 \\
\hline Ind. Transformação & 31 & -877 & 1608 & 231 & -6619 & -1486 & 52 & -1492 & -438 & 27 & -773 & -1323 \\
\hline Serv. I. U. Pública & 7 & -218 & -248 & 8 & -266 & 682 & 1 & -47 & 189 & 1 & -36 & 27 \\
\hline Ind. Constr. Civil & 15 & -491 & 232 & 46 & -1486 & 2755 & 6 & -210 & -24 & 35 & -1134 & -2739 \\
\hline Comércio & 73 & 897 & 4336 & 132 & 1627 & 3312 & 46 & 567 & 566 & 32 & 395 & 1321 \\
\hline Serviços & 128 & 1970 & 5102 & 232 & 3573 & 4054 & 59 & 912 & 2601 & 90 & 1379 & 2699 \\
\hline Administr. Pública & 111 & -986 & 2801 & 115 & -1015 & 6068 & 40 & -351 & 1047 & 21 & -188 & 1956 \\
\hline Agropecuária & 20 & -463 & 565 & 38 & -884 & -2294 & 10 & -224 & 389 & 4 & -98 & -49 \\
\hline
\end{tabular}

O efeito total, obtido pela soma dos efeitos estrutural e regional, e correspondente à diferença entre a variação efetiva e a teórica, é apresentado na Tabela 3. De um modo geral, o efeito total espelha os valores obtidos para 
o efeito regional, anteriormente descritos, o que não ocorre somente nos casos em que o efeito estrutural se sobressai. Assim, na região Metropolitana, apenas os setores Comércio e Serviços, nos quais o efeito estrutural superou o efeito regional negativo, apresentam efeito total positivos.

Nas demais regiões, foi constatado efeito total negativo nos setores: Serviços e Administração pública, na região Noroeste; Indústria extrativa mineral, Indústria de transformação e Serviços industriais de utilidade pública, na região Norte; Indústria de transformação, Serviços industriais de utilidade pública e Indústria da construção civil, na região Serrana; Serviços industriais de utilidade pública, Indústria extrativa mineral e Indústria da construção civil, nas Baixadas Litorâneas; Indústria de transformação e Agropecuária, no Médio Paraíba; Indústria de transformação, Indústria extrativa mineral e Indústria da construção civil, no Centro-Sul; e Indústria de transformação, Indústria da construção civil, Serviços industriais de utilidade pública e Agropecuária, na Costa Verde.

Logo, também pelo efeito total, fica evidenciado o maior dinamismo das economias das regiões interioranas. Nesse aspecto, destacam-se, principalmente, as regiões Noroeste e Médio Paraíba, nas quais a maioria dos setores apresentou crescimento superior ao observado no Estado como um todo, com exceção de Serviços e Administração pública, na primeira, e da Indústria de transformação e da Agropecuária, na segunda.

Tabela 3 - Efeito total (efeito estrutural mais regional) sobre o pessoal ocupado nas atividades econômicas das mesorregiões do estado do Rio de Janero, 1996-2000

\begin{tabular}{|c|c|c|c|c|c|c|c|c|}
\hline $\begin{array}{l}\text { Atividade } \\
\end{array}$ & Metropol. & Noroeste & Norte & Serrana & Baix. Litor. & M. Paraíba & Centro-Sul & Costa Verde \\
\hline Ind. Extr. Mineral & -196 & 212 & -3133 & 31 & -656 & 313 & -42 & 131 \\
\hline Ind. Transformação & -50244 & 1120 & -2784 & -3071 & 731 & -8105 & -1930 & -2096 \\
\hline Serv. I. U. Pública & -9049 & 29 & -340 & -901 & -466 & 417 & 142 & -9 \\
\hline Ind. Constr. Civil & -26396 & 79 & 3252 & -3 & -259 & 1269 & -233 & -3873 \\
\hline Comércio & 12134 & 1273 & 4608 & 3679 & 5233 & 4939 & 1133 & 1716 \\
\hline Serviços & 70674 & -177 & 10292 & 4453 & 7072 & 7628 & 3513 & 4078 \\
\hline Administr. Pública & -46230 & -525 & 734 & 4552 & 1815 & 5053 & 696 & 1768 \\
\hline Agropecuária & -1758 & 24 & 597 & 146 & 102 & -3178 & 165 & -147 \\
\hline
\end{tabular}

Fonte: dados da pesc

Pela análise feita, pode-se considerar que esse período, caracterizado por um processo de desconcentração e interiorização, foi também marcado pela estagnação econômica e pela menor capacidade de geração de emprego no conjunto da economia fluminense, como ficou evidenciado pelo pequeno efeito teórico. A estagnação da oferta de empregos formais esteve associada à implementação do novo modelo econômico brasileiro, caracterizado pela racionalização e desconcentração do gasto público e, também, pela privatização do setor produtivo estatal. A abertura da economia ao comércio e aos fluxos de capitais internacionais, o programa de privatizações e o fim do processo inflacionário deveriam promover um ambiente favorável, minimizando distorções de mercado, gerando incremento de produtividade, proporcionando estabilidade para os investimentos e trazendo, como efeito, possibilidades promissoras ao crescimento. Entretanto, essas ações foram ineficazes para promover mudanças na realidade socioeconômica do Brasil, e em particular do Estado do Rio de Janeiro. (DAMASCENO; ARAÚJO, 2003)

Esse período evidencia a crise, iniciada na década anterior, do modelo de desenvolvimento até então adotado pelo governo brasileiro, intrinsecamente vinculado à forte presença estatal nos investimentos e no planejamento da economia. A redução da presença estatal e a maior abertura do mercado nacional à concorrência internacional, especialmente a partir dos anos 90, evidenciaram a incapacidade da produção interna de competir com os produtos estrangeiros, o que levou várias empresas, nacionais ou não, a se reestruturarem organizacional e produtivamente. (ALMEIDA, 2002)

A situação do período seguinte (2000-2005) é distinta, pois, como pode ser observado no Gráfico1, o ano de 2000 marca uma retomada significativa do crescimento da economia fluminense, com possíveis reflexos no nível de emprego em suas diversas atividades. As mudanças desse período refletem o processo de reestruturação produtiva do país, bem como do Estado do Rio de Janeiro, combinando ampliação do saldo comercial com elevação do nível geral de emprego. Essa retomada de crescimento é, segundo algumas análises (FERNANDES, 2007; SILVA NETO, 2006), reflexo da ampliação da expansão da atividade petrolífera, que, através de seus encadeamentos, exerce forte efeito multiplicador sobre as demais cadeias produtivas.

Gráfico 1: Índice de crescimento do PIB do Estado do Rio de Janeiro no período de 1996 a 2005 (Base $1996=1000$ )

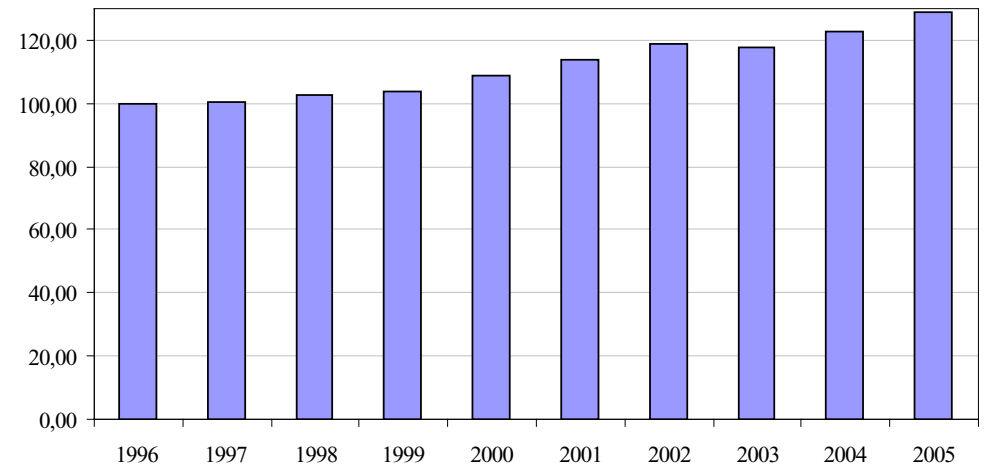

Fonte: dados originais da Fundação Cide (elaboração dos autores) 
Os resultados da decomposição da variação total do pessoal ocupado, ocorrida no período de 2000 a 2005, encontram-se nas Tabelas 4 e 5 . Nesse período, como no anterior, a variação teórica do pessoal ocupado mantém-se positiva, evidenciando a continuidade do crescimento do emprego total no Estado. Esse crescimento mostra-se, porém, bem mais elevado do que no quinquênio anterior, com efeitos teóricos significativamente superiores, refletindo, certamente, o maior crescimento econômico experimentado neste quinquênio. Nesse período, a Indústria extrativa mineral, o Comércio e a Agropecuária destacaram-se como os setores mais dinâmicos do Estado, com efeito estrutural positivo e apresentando, portanto, crescimento superior ao dos demais setores.

Tabela 4 - Decomposição da variação total do pessoal ocupado nos efeitos teórico (T), estrutural (E) e regional (R), para as regiões Metropolitana, Noroeste Fluminense, Norte Fluminense e Serrana, 2000-05

\begin{tabular}{|c|c|c|c|c|c|c|c|c|c|c|c|c|}
\hline \multirow[b]{2}{*}{ Atividade } & \multicolumn{3}{|c|}{ Metropolitana } & \multicolumn{3}{|c|}{ Noroeste } & \multicolumn{3}{|c|}{ Norte } & \multicolumn{3}{|c|}{ Serrana } \\
\hline & $\mathrm{T}$ & $\mathrm{E}$ & $\mathrm{R}$ & $\mathrm{T}$ & $\mathrm{E}$ & $\mathrm{R}$ & $\mathrm{T}$ & $\mathrm{E}$ & $\mathrm{R}$ & $\mathrm{T}$ & $E$ & $\mathrm{R}$ \\
\hline Ind. Extr. Mineral & 627 & 2597 & -2914 & 91 & 378 & -498 & 828 & 3431 & 6200 & 45 & 186 & -262 \\
\hline Ind. Transformação & 37472 & -12727 & -14020 & 910 & -309 & -339 & 1752 & -595 & 5275 & 4871 & -1654 & 1917 \\
\hline Serv. I. U. Pública & 6039 & -2165 & -3504 & 73 & -26 & -30 & 106 & -38 & 1468 & 299 & -107 & -58 \\
\hline Ind. Constr. Civil & 13328 & -2830 & -6814 & 97 & -21 & -88 & 1374 & -292 & 3760 & 698 & -148 & 66 \\
\hline Comércio & 64982 & 37996 & -10635 & 1162 & 679 & 1118 & 3317 & 1939 & 4714 & 4519 & 2642 & -1371 \\
\hline Serviços & 178258 & -17224 & -34314 & 1265 & -122 & 1106 & 6358 & -614 & 12631 & 7777 & -751 & -2904 \\
\hline Administr. Pública & 78033 & -11372 & -34855 & 1368 & -199 & 2716 & 2549 & -372 & 11459 & 3158 & -460 & -41 \\
\hline Agropecuária & 684 & 114 & -206 & 396 & 66 & -172 & 907 & 151 & 832 & 663 & 110 & -372 \\
\hline
\end{tabular}
Fonte: dados da pesquisa

Tabela 5- Decomposição da variação total do pessoal ocupado nos efeitos teórico (T), estrutural (E) e regiona R), para as regiões Baixadas Litorâneas, Médio Paraíba, Centro-Sul Fluminense e Costa Verde, 2000-05

\begin{tabular}{|c|c|c|c|c|c|c|c|c|c|c|c|c|}
\hline \multirow[b]{2}{*}{ Atividade } & \multicolumn{3}{|c|}{ Baixadas Litorâneas } & \multicolumn{3}{|c|}{ Médio Paraíba } & \multicolumn{3}{|c|}{ Centro-Sul } & \multicolumn{3}{|c|}{ Costa Verde } \\
\hline & $T$ & $\mathrm{E}$ & $\mathrm{R}$ & $\mathrm{T}$ & & $\mathrm{R}$ & $\mathrm{T}$ & $\mathrm{E}$ & $\mathrm{R}$ & T & $\mathrm{E}$ & $\mathrm{R}$ \\
\hline Ind. Extr. Mineral & 183 & 758 & -917 & 123 & 511 & -1086 & 32 & 134 & 21 & 121 & 501 & -544 \\
\hline Ind. Trans & 973 & -331 & 393 & 4969 & -1688 & 1401 & 1102 & -374 & -1 & 380 & -129 & 5373 \\
\hline Serv. I. U. Pública & 107 & -38 & 538 & 302 & -108 & -370 & 66 & -24 & 705 & 30 & -11 & 1251 \\
\hline Ind. Constr. Civil & 375 & -80 & 2608 & 1491 & -317 & -1456 & 138 & -29 & 1438 & 294 & -62 & 487 \\
\hline Comércio & 2928 & 1712 & 6258 & 4518 & 2642 & -897 & 1472 & 861 & 88 & 1187 & 694 & 725 \\
\hline Serviços & 4765 & -460 & 11158 & 7738 & -748 & 1527 & 2248 & -217 & 675 & 3184 & -308 & 10120 \\
\hline Administr. Pública & 3392 & -494 & 11987 & 4046 & -590 & -398 & 1215 & -177 & 1353 & 894 & -130 & 7779 \\
\hline Agropecuária & 568 & 94 & -437 & 495 & 82 & 115 & 294 & 49 & 174 & 91 & 15 & 65 \\
\hline
\end{tabular}

Em nível regional, o período acentua a constatação de menor dinamismo da região Metropolitana, onde o efeito regional é negativo para todos os setores. Porém, há diferenças entre o comportamento das demais regiões, nem todas elas beneficiando-se do processo de interiorização constatado no período precedente.

Assim, observa-se efeito regional negativo nos setores: Indústria extrativa mineral, Indústria de transformação, Serviços e Administração pública,
Indústria da construção civil e Agropecuária, na região Noroeste; em praticamente todos os setores na região Serrana, com exceção das Indústrias de transformação e da construção civil; Indústria extrativa mineral e Agropecuária, nas Baixadas Litorâneas; e Indústria extrativa mineral, Serviços industriais de utilidade pública, Indústria da construção civil, Comércio, Administração pública e Agropecuária, no Médio Paraíba. Por outro lado, esse período é marcado por condições mais propícias ao crescimento dos setores analisados na região Norte, e também nas regiões Centro Sul e Costa Verde, nas quais se observa efeito regional positivo para todos ou quase todos os setores.

A soma dos efeitos estrutural e regional, correspondente ao efeito total, resulta nas informações constantes da Tabela 6. Esses resultados, que em grande medida refletem o efeito regional, mostram um comportamento menos dinâmico da região Metropolitana, na qual, com exceção do setor de Comércio, todos os demais apresentam crescimento inferior ao crescimento do emprego total na economia fluminense. Situação semelhante é observada nas regiões Noroeste, Serrana e Médio Paraíba, nas quais apenas os setores Comércio, Serviços e Administração Pública, na primeira, Indústria de Transformação e Comércio, na segunda, e Comércio, Serviços e Agropecuária, na terceira, apresentaram efeito total positivo.

Tabela 6 - Efeito total (efeito estrutural mais regional) sobre o pessoal ocupado nas atividades econômicas das mesorregiões do Estado do Rio de Janeiro, 2000-2005

\begin{tabular}{lcccccccc}
\hline Atividade & Metropol. & Noroeste & Norte & Serrana & Baix. Litor. & M. Pará́ba & Centro-Sul & Costa Verde \\
\hline Ind. Extr. Mineral & -317 & -119 & 9631 & -77 & -159 & -574 & 155 & -44 \\
Ind. Transformação & -26747 & -648 & 4680 & 262 & 63 & -287 & -375 & 5244 \\
Serv. I. U. Pública & -5669 & -56 & 1430 & -165 & 500 & -478 & 681 & 1240 \\
Ind. Constr. Civil & -9644 & -109 & 3468 & -82 & 2528 & -1773 & 1409 & 424 \\
Comércio & 27361 & 1798 & 6653 & 1271 & 7970 & 1744 & 948 & 1419 \\
Servicicos & -51538 & 984 & 12017 & -3656 & 10698 & 780 & 457 & 9813 \\
Administr. Pública & -46227 & 2516 & 11088 & -501 & 11493 & -987 & 1176 & 7649 \\
Agropecuária & -92 & -106 & 983 & -261 & -343 & 197 & 223 & 80 \\
\hline
\end{tabular}

Fonte: dados da pesquisa

Por outro lado, fica evidente o maior dinamismo da região Norte, onde o crescimento do emprego é, em todos os setores, superior ao crescimento do emprego no Estado. Oliveira (2003) afirmava que as expectativas para o desenvolvimento do setor extrativo eram maiores para a região metropolitana, já que nela se encontra a maior parte da estrutura industrial e de serviços do Estado. De certo modo, ainda que 
não contrariem essa afirmação, os resultados aqui obtidos evidenciam que a região Norte tem, sim, se beneficiado significativamente desse processo. Essa situação ocorre também nas regiões Baixadas Litorâneas, Centro-Sul e Costa Verde, nas quais o efeito total é predominantemente positivo, com exceção dos setores: Indústria Extrativa Mineral e Agropecuária, Indústria de Transformação e Indústria Extrativa Mineral, respectivamente.

O processo de desconcentração e interiorização da economia fluminense, identificado na análise feita, pode ser também constatado na Tabela 7, que apresenta o comportamento da participação das distintas regiões no PIB do Estado. Responsável, em 1999, por 72\% do PIB fluminense, a região metropolitana reduz expressivamente essa participação ao longo do período, respondendo, em 2004 , por $62 \%$ do produto estadual. Trata-se, portanto, de uma desconcentração significativa, considerando-se que ela se deu num período relativamente curto. Conforme Freire, Feijó e Carvalho (2004), o processo de reestruturação produtiva na economia fluminense tem resultado no desenvolvimento de cidades médias no interior, denominadas de "capitais regionais", tais como Volta Redonda (Médio Paraíba) e Macaé (Norte Fluminense), possibilitando redução da concentração econômica na capital do Estado.

Tabela 7 - Distribuição do PIB Fluminense pelas Regiões de Governo (\%)

\begin{tabular}{lrrrrrr}
\hline Região & 1999 & 2000 & 2001 & 2002 & 2003 & 2004 \\
\hline Bacia de Campos & 10,89 & 18,57 & 18,99 & 16,45 & 17,77 & 18,96 \\
Baixadas Litorâneas & 2,06 & 1,80 & 1,78 & 1,90 & 2,17 & 2,11 \\
Centro-Sul Fluminense $^{1}$ & 0,81 & 0,73 & 0,69 & 0,73 & 0,84 & 0,79 \\
Costa Verde $^{2}$ & 1,33 & 1,12 & 1,22 & 1,58 & 1,33 & 1,44 \\
Médio Paraíba & 6,00 & 5,67 & 5,94 & 6,58 & 7,74 & 8,41 \\
Metropolitana & 72,05 & 66,58 & 65,90 & 66,65 & 63,59 & 61,90 \\
Noroeste Fluminense & 0,87 & 0,72 & 0,69 & 0,65 & 0,78 & 0,70 \\
Norte Fluminense & 2,34 & 2,00 & 2,28 & 2,82 & 2,95 & 3,00 \\
Serrana & 3,65 & 2,81 & 2,52 & 2,66 & 2,83 & 2,69 \\
\hline
\end{tabular}

Obs.: ' Refere-se à extração de petróleo e gás natural na Bacia de Campos; ${ }^{2}$ Até 2001

essa região era denominada Baia da Ilha Grande

Fonte: Fernandes (2007)

No contexto da metodologia aqui empregada, setores crescem ou decrescem mais rapidamente em uma região do que em outras em resposta a vantagens ou desvantagens daquela região relativamente às demais.
De acordo com Santos (2000), aspectos como variação nos custos dos transportes, estímulos fiscais, diferenças de preços relativos de insumos e fatores de produção mais abundantes contribuem para conferir vantagens locacionais a determinada região.

Antes, porém, de abordar possíveis causas do processo de interiorização, é importante destacar que, conforme Barral Neto e Silva Neto (2006), tal processo, mantidas as peculiaridades regionais, é reflexo de uma tendência mundial, razão pela qual não deve ser percebido como um movimento existente exclusivamente no Estado do Rio de Janeiro. Segundo os autores, as indústrias têm se afastado dos espaços metropolitanos, direcionando-se para o interior, em busca de externalidades favoráveis, tais como incentivos fiscais, recursos mais baratos e sindicatos pouco organizados.

No caso do Estado do Rio de Janeiro, segundo os autores, esse processo não pode ser visto como uma expansão das atividades industriais para o interior fluminense, mas sim de um resgate de bases produtivas atrasadas tecnologicamente e incapazes de se reestruturar. Este processo passa a reestruturar atividades tradicionais através do crescimento de outros polos espalhados no território fluminense. (BARRAL NETO; SILVA NETO, 2006)

Por outro lado, as mudanças introduzidas na constituição 1988 deram maior autonomia aos governos estaduais e municipais, a partir de um forte instrumento de política regional, o ICMS, junto com outras fontes de concessão. Este pode ser um dos fatores que mais contribuíram para o processo de desconcentração econômica. A redução de impostos municipais para atrair maiores investimentos externos, na chamada "guerra fiscal", pode ter incentivado o processo de interiorização da economia fluminense.

De acordo com Barral Neto e Silva Neto (2006), em se tratando do Estado do Rio de Janeiro, são relevantes os impactos provocados pela "guerra fiscal", na qual impostos municipais, como ISS, IPTU e taxas de água, foram reduzidos ou mesmo isentos para as empresas investidoras. Essas estratégias fiscais contribuíram para a atração de investimentos para as diversas regiões do interior do Estado, conferindo-lhes maior independência em relação à região metropolitana para melhor configurarem suas economias.

Por outro lado, os mesmos autores ressaltam que as estratégias fiscais, isoladamente, não explicam a recente recuperação e reestruturação econômica do Estado do Rio de Janeiro e o processo de interiorização de sua economia. O principal fator, de acordo com os autores, foi o aumento das atividades extrativistas, essenciais tanto no processo de recuperação econômica, quanto no aprofundamento da interiorização. 
O maior dinamismo da indústria extrativa mineral, observado no estudo, é uma evidência de que a expansão dessa indústria, fortemente calcada na exploração petrolífera, tem sido um fator primordial no processo de retomada do crescimento econômico e da geração de empregos no Estado. Segundo Freire, Feijó e Carvalho (2004), após a retomada das atividades econômicas em 1999, houve um aumento da participação do PIB fluminense no PIB nacional. Trata-se, segundo Sobral (2007), de uma inédita inflexão econômica positiva na trajetória declinante da participação do Estado na economia do país. Para Freire, Feijó e Carvalho (2004), esse crescimento foi impulsionado pelo aumento da extração de petróleo e gás e pela fabricação de material de transporte, com a implantação de novas montadoras no Estado.

E, como revelam os dados da Tabela 7, esse processo acarretou forte elevação da participação da Bacia de Campos no PIB estadual, que praticamente dobra no período considerado, elevando-se de $10,89 \%$ para $18,96 \%$. Isso beneficiou ainda as regiões Médio Paraíba e Norte Fluminense6, cujas participações se elevaram em alguma medida, em detrimento, além da região Metropolitana, também da região Serrana, cuja participação no PIB estadual sofreu redução no período. As atividades petrolíferas têm sido a base da reestruturação econômica e produtiva do Estado, em particular da região Norte Fluminense, por recuperar bases produtivas, ditar a dinâmica econômica e urbana de seus municípios, retomando o crescimento econômico e elevando os orçamentos municipais, com a distribuição dos royalties. (BARRAL NETO; SILVA NETO, 2006)

\section{Conclusões}

Os resultados da análise permitem inferir que o Estado do Rio de Janeiro passou por um processo de descontração e interiorização de sua economia na última década. Tal processo implicou num crescimento mais elevado do emprego nas atividades situadas nas regiões do interior do Estado do que na região metropolitana, onde, tradicionalmente, estão concentrados o emprego e a renda.

Esse processo aconteceu na segunda metade da década de noventa, e se acentuou na primeira metade da década seguinte. Enquanto o primeiro

${ }^{6}$ Como as informações relativas a petróleo e gás foram desmembradas das mesorregiões em que esses produtos são extraídos, e colocadas à parte, na Bacia de Campos, a participação da região Norte, que concentra a maior parte destas atividades, fica altamente subestimada. período caracterizou-se por relativa estagnação, com destaque apenas para os setores de Comércio e de Serviços, a primeira metade da década seguinte foi marcada por maior geração de renda e emprego. Nesse segundo período, a Indústria extrativa mineral, o Comércio e a Agropecuária destacaram-se como os setores mais dinâmicos do Estado.

As mudanças introduzidas a partir da constituição 1988, que deram maior autonomia aos governos estaduais e municipais, podem ser um dos fatores que contribuíram para o processo de desconcentração econômica. A redução de impostos municipais para atrair maiores investimentos externos, na chamada "guerra fiscal", pode ter incentivado o processo de interiorização da economia fluminense.

Porém, como relatam alguns estudos, esse fator é incapaz de, isoladamente, explicar as mudanças observadas. Dentre outros fatores que contribuíram para isso, há que se destacar o aumento das atividades extrativistas, setor chave na explicação da recuperação econômica e do aprofundamento da interiorização da economia do Estado. O maior dinamismo da Indústria extrativa mineral, observado no estudo, é uma evidência de que a expansão da indústria extrativa mineral, fortemente calcada na exploração petrolífera, tem sido um fator primordial no processo de retomada do crescimento econômico e da geração de empregos no Estado.

Os resultados aqui obtidos evidenciam a desconcentração e a interiorização da economia fluminense. Porém, em face do estágio inicial em que se encontra a pesquisa, o presente texto não analisa com profundidade as causas das alterações constatadas, que são apenas abordadas como hipóteses, nem os possíveis impactos econômicos e sociais delas decorrentes, que serão alvo de futuros estudos.

\section{Referências}

ALCÂNTARA, M. M. P. O setor industrial no estado do Rio de Janeiro: uma análise espaço temporal. 2005. 133 f. Dissertação (Mestrado em Estudos Populacionais e Pesquisas Sociais) - Escola Nacional de Ciências Estatísticas. Rio de Janeiro

ALMEIDA, S. V. A reestruturação produtiva da indústria brasileira na década de 1990: uma analise dos setores têxtil, calçadista e automobilístico. 2002. 148 f. Dissertação (Mestrado em Sociologia) - Instituto Universitário de Pesquisa, Rio de Janeiro. 
BARRAL NETO, J.; SILVA NETO, R. Reestruturação produtiva e interiorização da economia no estado do Rio de Janeiro: uma nova dinâmica para a região norte fluminense. In: ENCONTRO NACIONAL DE ESTUDOS POPULACIONAIS, 15, 2006, Caxambu -MG. Anais... Campinas: ABEP, 2006.

BRASIL. Ministério do Trabalho e Emprego. Programa de Disseminação das Estatísticas do Trabalho: registros administrativos (PDET). Brasil:

MTE. Disponível em: < http://www.mte.gov.br/Estudiosos Pesquisadores/PDET/ REGISTROS.asp > Acesso em: 30 mar. 2008.

CIDE. Fundação Centro de Informações e Dados do Rio de Janeiro. Disponível em: <http://www.cide.rj.gov.br> . Acesso em: 31 mar. 2008.

\section{DAMASCENO, A. O.; ARAÚJO, R. D. Crescimento econômico e}

reformas: a economia brasileira na década de 90 e perspectivas. Bahia

Análise \& Dados, Salvador, v. 13, n. 3, p. 757-768, dez. 2003

FERNANDES. C. F. A evolução da arrecadação de royalties do petróleo no Brasil e seu impacto sobre o desenvolvimento econômico do estado do Rio de Janeiro. 2007. 72 f. Monografia, (Bacharelado em Economia, Instituto de Economia), - Universidade Federal do Rio de Janeiro Rio de Janeiro, Rio de Janeiro.

FREIRE, D. G., FEIJÓ, C. A., CARVALHO, P. G. M. A economia do estado do Rio de Janeiro na segunda metade dos anos 90. ENCONTRO NACIONAL DE ECONOMIA POLÍTICA, 9., 2004, Uberlândia. Anais... Uberlândia: SEP, 2004.

HADDAD, P. R., ANDRADE, T. A. Método de análise diferencial estrutural. In: HADDAD, P. R. (Org.). Economia regional: teorias e métodos de análise. Fortaleza: Banco do Nordeste do Brasil, 1989, p. 249-286.

OLIVEIRA, F. G. Reestruturação produtiva e regionalização da economia no território fluminense. 2003. 231 f. Tese (Doutorado em Geografia Humana ) - Programa de Pós-Graduação em Geografia Humana, Departamento de Geografia, Faculdade de Filosofia, Letras e Ciências Humanas, Universidade de São Paulo, São Paulo.

PEREIRA, A. S. O método estrutural-diferencial e suas reformulações. Teoria e Evidência Econômica, Passo Fundo, v. 5, n.9, p. 93-105, maio 1997.

PEREIRA, A. S.; CAMPANILE, N. O método estrutural-modificado: uma aplicação para o estado do Rio de Janeiro entre 1986 e 1995. Teoria e Evidência Econômica, Passo Fundo, v. 7, n. 13, p. 121-140, nov. 1999.
SANTOS, A. M. S. P. Economia, espaço e sociedade no Rio de laneiro. Rio de Janeiro: Editora FGV, 2003. v. 1, 228 p.

SANTOS, S. R. O método estrutural-diferencial ampliado: uma aplicação para a região sul frente à economia do rio grande do sul, entre 1986 e 1995. Teoria e Evidência Econômica, Passo Fundo, v. 8 n. 15 p 25-45, nov. 2000.

SILVA NETO, R. Indústria e desenvolvimento na região Norte Fluminense: crescimento econômico e o problema da extrema heterogenidade econômico-espacial no Estado do Rio de Janeiro. In. CARVALHO, Ailton Mota de; TOTTI, Maria Eugenia Ferreira (Org.). Formação histórica e econômica do Norte Fluminense. Rio de Janeiro: Garamond, 2006. p. 225-274.

SILVA, R. D. Crescimento, transformações e sua importância para a economia nacional (1930 a 2000). 2004. 166f. Dissertação (Mestrado) - Programa de Pós-Graduação em Ciências Econômicas, Instituto de Economia, Unicamp, Campinas, 2004.

SOBRAL, B. L. B. Desconcentração produtiva regional no Brasil: análise do estado do Rio de Janeiro: 1970/2006. Campinas-SP: Unicamp, Instituto de Economia, 2007.

SOUZA, M. A. A. Geração de emprego na pesca industrial em rio grande: uma aplicação do método estrutural-diferencial. In: CONGRESSO DA SOBER, 45, 2007, Londrina-PR. Anais... Brasília-DF: SOBER, 2007. p. 1-12.

SOUZA, N. J.; SOUZA, R. B. L. Dinâmica estrutural-diferencial da região metropolitana de porto alegre, 1990/2000. Economia, v. 30, n. 2, p. 121-144, jul./dez. 2004.

SOUZA, P. M. et al. Evolução da mão-de-obra ocupada na agricultura dos municípios das regiões norte e noroeste do estado do Rio de Janeiro, 1970 a 1995. Informe Gepec, Londrina, v. 10, p. 107-131, 2007. 



\section{Colofão}

\begin{tabular}{r|l} 
Formato & $17 \times 24 \mathrm{~cm}$ \\
Tipologia & CG Omega \\
& $\begin{aligned} 75 \mathrm{~g} / \mathrm{m}^{2} \text { (miolo) } \\
\text { Cartão Supremo } 250 \mathrm{~g} / \mathrm{m}^{2} \text { (capa) }\end{aligned}$ \\
Impressão & $\begin{array}{l}\text { Setor de Reprografia da EDUFBA } \\
\text { Capáfica ESB }\end{array}$ \\
Tiragem & 300 exemplares \\
&
\end{tabular}

